\title{
Müller Cells Are a Preferred Substrate for in vitro Neurite Extension by Rod Photoreceptor Cells
}

\author{
Ivar J. Kljavin ${ }^{1}$ and Thomas A. Reh² \\ 'Neuroscience Research Group, Faculty of Medicine, Lion's Sight Center, University of Calgary, Calgary, Alberta, Canada \\ T2N 1N4 and 'Department of Biological Structure, University of Washington, Seattle, Washington 98195
}

\begin{abstract}
To define the factors important in photoreceptor cell morphogenesis, we have examined the ability of rods to extend neurites in vitro. Retinas from neonatal rats were dissociated and plated onto substrate-bound extracellular matrix (ECM) components or cell monolayers. When rods, identified with monoclonal antibodies to opsin, were in contact exclusively with purified ECM (e.g., laminin, fibronectin, type I collagen, or Matrigel), neurite outgrowth was extremely limited. By contrast, rods extended long neurites on Müller cells. Retinal or brain astrocytes, endothelial cells, 3Т 3 fibroblasts, or other retinal neurons were less supportive of rod process outgrowth. These data demonstrate regional specificity in the promotion of neurite outgrowth by glia and suggest that not all neurons within the retina require the same morphogenic factors.
\end{abstract}

During the development of the CNS, the morphogenesis of neurons appears to be regulated, in part, by intercellular interactions. Studies of neurons from various CNS regions have shown that selective interactions between the growth cones and the surrounding extracellular matrix (ECM) or glial cell surfaces are responsible for guiding the growing axons to their proper targets (Sidman and Wessels, 1975; Silver and Sapiro, 1981; Silver et al., 1982; Liesi, 1985). These previous studies have concentrated primarily on neurons that project their axons over long distances, typically along the end feet of the neuroepithelial cells or radial glial cells of the developing CNS. In the retina, for example, most studies have focused on axonal growth of retinal ganglion cells, the retinal projection neuron. Their growth cones, like those of other projection neurons, come in contact with the end feet of the neuroepithelial cells in the retina, as well as astroglia in the optic nerve (Rager, 1980; Easter et al., 1984; McLoon et al., 1988). In addition, the axons of these neurons, like those of other projection neurons, have a strong tendency to fasciculate with other axons in the developing optic nerve

\footnotetext{
Received Mar. 1, 1991; revised Apr. 24, 1991; accepted Apr. 26, 1991.

We thank A. Ertlmaier, E. Gonzalez, and M. Walker for technical assistance and K. Graybeal for typing the manuscript. We also thank Dr. P. V. Sarthy for preparing the adult Müller cells and critically reading the manuscript and Dr. C. Lagenauer for helpful discussions. T.A.R. is a Sloan Foundation Fellow. I.J.K. is supported by a studentship at the University of Calgary from the Alberta Heritage Foundation for Medical Research, Canada. This work is in partial fulfillment for the degree requirements of Ph.D. to I.J.K. and was supported by a grant from the National Retinitis Pigmentosa Foundation of Canada and NIH Grant R01 NS23808.

Correspondence should be addressed to Dr. T. A. Reh, Department of Biological Structure, SM-20, University of Washington, Seattle, WA 98195.

Copyright (C) 1991 Society for Neuroscience $0270-6474 / 91 / 112985-10 \$ 05.00 / 0$
}

(Silver and Sidman, 1980; Krayanek and Goldberg, 1981). Additional studies have begun to characterize the molecules that are responsible for regulating the growth of ganglion cell axons during development, and it appears that many of the ECM and cell adhesion molecules involved in axon outgrowth are concentrated on the neuroepithelial cell end feet along these long tracts (Silver and Rutishauser, 1984; Halfter et al., 1988).

However, during the normal development of the retina, as well as other areas of the CNS, most neurons do not extend axons into long pathways, but rather, their axons terminate on neighboring cells. In the retina, for example, the axons of the majority of neurons will never come into contact with the end feet of the neuroepithelial cells or the astrocytes of the ganglion cell fiber layer and optic nerve. Recent studies by Denis-Donini and her colleagues (Denis-Donini et al., 1984; Denis-Donini and Estenoz, 1988) indicate that at least some projection neurons and interneurons respond differently to their glial environment: the mesencephalic dopaminergic projection neurons differ from periglomerular interneurons in their ability to extend processes on glial cells cultured from either the mesencephalon or the olfactory bulb. To determine the types of intercellular interactions that are normally involved in the development of processes from retinal nonprojection neurons, we undertook an in vitro study of the factors that promote neurite extension from one class of these cells, the rod photoreceptor cells. Previous in vivo studies have described the morphogenesis of photoreceptor cells. Serial section electron microscopic studies by Hinds and Hinds (1979) have shown that after rounding up at their terminal mitosis, photoreceptor cells develop a rudimentary outer segment (and therefore can be reliably identified) followed by the reextension of their vitreal/presynaptic terminal process. Since rods arise at approximately the same time as Müller cells during retinal histogenesis (Carter-Dawson and LaVail, 1979; Turner and Cepko, 1988; Zimmerman et al., 1988) and the two cell types are intermingled throughout their maturation, we were particularly interested in whether this intrinsic retinal glial cell plays an important role in rod photoreceptor cell morphogenesis.

We have found that Müller cells promote extensive neurite outgrowth from rods; however, astrocytes (retinal or cortical), endothelial cells, 3T3 cells, or purified ECM components provide much less effective substrates for process extension from these cells. These results demonstrate the importance of the intrinsic retinal Müller glial cells in rod morphogenesis and indicate the presence of regional heterogeneity in the ability of glial cells to support neurite outgrowth from particular classes of neurons within the CNS. 


\section{Materials and Methods}

Dissociated retinal cultures. Sprague-Dawley or Long Evans rat pups, 3-5 d of age, were killed by decapitation following ether anesthesia, and the eyes were removed under sterile conditions. The neural retina was dissected away from the pigment epithelium and other ocular tissue in sterile basal salt solution (BSS). The retinas were dissociated into a single-cell suspension using the following protocol. (1) A single retina was placed in $5 \mathrm{ml}$ of $\mathrm{Ca}^{2+}, \mathrm{Mg}^{2+}$-free BSS; (2) the retina was incubated at room temperature in this solution for $20 \mathrm{~min}$, and then $0.5 \mathrm{ml}$ of a $2.5 \%$ trypsin solution was added; (3) the incubation was continued for another $20 \mathrm{~min}$, after which time $0.5 \mathrm{ml}$ of fetal bovine serum was added to inactivate the trypsin; (4) the retina was then spun to a pellet, and the supernatant was removed; (5) fresh BSS $(5 \mathrm{ml})$ was then added, and the retinas were then triturated to a single-cell suspension; (6) the cells were then plated in either Dulbecco's modified Eagle's medium (DMEM) (GIBCO) with 10\% fetal bovine serum (FBS), glutamine, and antibiotics added, or DMEM:F1 2 (without glutamate or aspartate; GIBCO) supplemented with insulin $(25 \mu \mathrm{g} / \mathrm{ml})$, transferrin $(100 \mu \mathrm{g} / \mathrm{ml})$, putrescine $(60 \mu \mathrm{M})$, selenium ( $30 \mathrm{nM}$ ), progesterone ( $20 \mathrm{nM})$, and in some experiments (see Results), either $0.25 \%$ or $1 \%$ fetal calf serum. For all experiments, the retinal cells were maintained in low-serum media for the $24 \mathrm{hr}$ data and in $10 \%$ serum for the $6 \mathrm{~d}$ data.

For cultures testing rod process outgrowth on the surfaces of other retinal neurons (see Fig. 5), cultures were prepared by the following method. Retinal cells from postnatal day 3-5 were prepared for culture as described above $(50,000-100,000$ cells per well) and allowed to grow for 3-6 hr followed by a subsequent plating of retinal neurons (postnatal day $3-5,10,000-50,000$ cells per well) in order to increase the frequency of rods contacting other retinal neurons. The cultures were then allowed to continue for another $24 \mathrm{hr}$. The substrate for these experiments was either laminin $(10 \mathrm{ng} / \mathrm{ml})$ or poly-D-lysine (see below). One of several different media conditions were used: (1) serum free; (2) $0.25 \%$ serumcontaining media + basic fibroblast growth factor (bFGF); (3) $1 \%$ serumcontaining media; or (4) $1 \%$ serum-containing media $+b F G F+a$ mitotic inhibitor [10-5 mM cytosine arabinoside (AraC)]. Cells for all experiments were grown at $37^{\circ} \mathrm{C}$ in an atmosphere of $5 \% \mathrm{CO}_{2}$.

Preparation of culture substrates. Glass coverslips were first coated with poly-D-lysine $(50-100 \mu \mathrm{g} / \mathrm{ml})$ and then either laminin $(0.1,1,5$, $10,50,100 \mu \mathrm{g} / \mathrm{ml}$; Collaborative Research, Boston, MA) or fibronectin $(0.1,1,5,10,50,100 \mu \mathrm{g} / \mathrm{ml}$; Collaborative Research). Collagen I (bovine dermal, Collaborative Research) was diluted to approximately $1 \mathrm{mg} /$ $\mathrm{ml}$ with BSS, and a thin coating was allowed to dry on the coverslip. Matrigel (Collaborative Research) was diluted 1:50 with BSS, and a thin coating was allowed to gel in the incubator for $30 \mathrm{~min}$.

Glial cell cultures. Adult Müller cell cultures were established by the method of Sarthy (1985). Briefly, retinas were dissected from 45-60-dold Sprague-Dawley rats that had been exposed to constant light for 3$7 \mathrm{~d}$. Retinas were then incubated in $\mathrm{Ca}^{2+}, \mathbf{M g}^{2}$-free Hanks' balanced salts solution (HBSS) containing $0.25 \%$ trypsin at $37^{\circ} \mathrm{C}$ for $20-30 \mathrm{~min}$. After this incubation, the tissue was rinsed in serum-containing media and dispersed into single cells by vigorous trituration. The cells were plated (approximately 100,000 cells/well) onto poly-D-lysine/laminin $(10 \mu \mathrm{g} / \mathrm{ml})$ - or Matrigel-coated coverslips placed into each well of a 24 well plate in $10 \%$ serum-containing media and cultured for $14-20 \mathrm{~d}$, until they became confluent. Examination of these cultures with Rho$4 D 2$ or A2B5 monoclonal antibodies revealed that no neurons were present in the Müller cell cultures following this procedure. Astrocytes were isolated from cerebral cortex of rat pups on the day of birth and dissociated as described above for retinal dissociations. The cultures were maintained in $10 \%$ serum-containing media and were purified for astrocytes according to published methods (Fallon, 1985). The cells were then plated (approximately 100,000 cells per well) onto poly-D-lysine/ laminin $(20 \mu \mathrm{g} / \mathrm{ml})$ - or Matrigel-coated coverslips placed into each well of a 24-well plate and allowed to form a confluent or near-confluent monolayer (3-7 d) before coculture with the retinal cells. Approximately $90 \%$ of the non-neuronal cells in these cultures were positive for glial fibrillary acid protein (GFAP) and appeared as large flat cells. Fibroblast monolayers were derived from the mouse Balb/c $3 \mathrm{~T} 3$ cell line that was maintained in $10 \%$ serum-containing media in $10 \mathrm{ml}$ tissue culture flasks. For the coculture experiments, the $3 T 3$ cells were removed from the flasks following treatment with $\mathrm{Ca}^{2+}, \mathrm{Mg}^{2+}$-free HBSS containing $0.25 \%$ trypsin at $37^{\circ} \mathrm{C}$ for $5 \mathrm{~min}$. Cells were plated $(50,000-100,000$ cells per well) onto poly-D-lysine/laminin $(20 \mu \mathrm{g} / \mathrm{ml})$-coated coverslips placed into each well of a 24-well plate and allowed to become confluent (about 2-4 d) prior to coculture with the retinal cells. For all the coculture experiments, the cells were maintained in low-serum media for the 24 hr data and in $10 \%$ serum for the $6 \mathrm{~d}$ data.

Immunohistochemical identification of cells in culture. Monoclonal antibodies against rhodopsin, Rho-4D2, and Rho-2A4 were obtained from a hybridoma cell line (the generous gift of Drs. R. Molday and D. Hicks, University of British Columbia; Hicks and Barnstable, 1987). Supernatant from hybridoma cells was used without dilution, while ascites from these cells was typically diluted 1:100. Monoclonal antibodies directed against glial fibrillary acid protein (GFAP) and vimentin were commercially obtained and used at the recommended dilutions (Boeringer Mannheim, Germany). Type IV collagen antisera (raised in rabbit) were obtained from Dr. H. Furthmayr, Department of Pathology, Yale University (Foellmer et al., 1983), and carbonic anhydrase antisera (raised in rabbit) were commercially obtained (Calbiochem, San Diego, CA). Polyclonal antisera, raised in rabhits against cellular retinaldehydebinding protein (CRALBP; Bunt-Milam and Sarri, 1983), were obtained from Dr. J. Sarri, University of Washington, and the monoclonal antibody A2B5 was obtained from hybridoma supernatant ( $\triangle$ merican Tissue Type Collection). Indirect immunofluorescent labeling was carried out using biotinylated secondary antibodies (anti-mouse or rabbit IgG from Sigma Chemical Co.; $10 \mu \mathrm{g} / \mathrm{ml}$ ) followed by avidin-letramethylrhodamine B isothiocyanate (TRITC; Sigma) or streptavidinfluorescein isothiocyanate (FITC; Molecular Probes, Eugene, OR). Omission of the primary antibody eliminated the observed immunoreactivity on the retinal cultures.

The double-labeled fluorescent micrographs (Fig. $1 A-C$ ) were prepared by the following protocol: (1) first primary antibody, (2) secondary biotinylated antibody, (3) avidin or streptavidin fluorochrome, (4) second primary antibody, and then repeat steps 2 and 3 with a different fluorochrome. The use of two biotinylated secondary antibodies with two different avidin fluorochromes results in intense labeling of both subject cell types; however, since both avidinatcd fluorochromcs will bind to the first biotinylated secondary antibody used, the first cell type stained will show both fluorochromes, while the second labeled cell in the sequence will be detected only by the last avidin fluorochrome used. For example, double color exposures (TRITC, red; FITC, green) such as in Figure $1 A$ yield yellow labeling of the rods. The rods in Figure $1 A$ were the first to be labeled with FITC, and the vimentin labeled flat cells were secondarily labeled with TRITC.

Analysis of rod photoreceptor cell process outgrowth. The growth of neurites from rods was examined after $1-6 \mathrm{~d}$ in culture (see Fig. $3 A, B$ ). The number of Rho-4D2-positive rods and number of experiments examined for each of the data points are indicated in the figure caption. For measurements of neurite length, the rods with processes were examined at a final image magnification of $400 \times$. The fluorescent images of the rods were recorded with an image intensifier coupled to a chargecoupled device (CCD) video camera (Motion Analysis, Eugene, OR) and analyzed with a Macintosh II image processing program (IMAGE ANALYSI, Automax, Billerica, MA). Neurite lengths were measured by tracing the total length of any neurite extending from a rod cell body. Recorded lengths were calibrated at the same magnification using a microscope slide micrometer.

\section{Results}

This study required a reliable method for identifying rod photoreceptor cells in culture. Therefore, we used the monoclonal antibodies (Rho-4D2 and Rho-2A4) directed against rhodopsin, which is found exclusively in rods in rat retina. These antibodies have been previously characterized in the developing and adult rat retina (Hicks and Barnstable, 1987), and we have also found that in cultured cells, the antibody labels the entire rod cell body and full extent of any processes. Figure $1 A$ (arrowheads) shows an example of the rhodopsin labeling that we observed in a culture from postnatal day 3 rat retina, fixed after $6 \mathrm{~d}$ in culture. The immunoreactivity is distributed throughout the entire cell soma and neurites. In addition, we have also examined the distribution of this antigen in cryostat sections of retinas from both prenatal and postnatal animals, fixed in a manner identical to our cultures; we found that the opsin immunoreactivity was localized exclusively to cells in the developing outer nuclear layer, as has been reported by others (see, e.g., Hicks and Barnstable, 1987). 
The non-neuronal cells that proliferate in dissociated postnatal retinal cultures (Fig. $1 A-C$ ) may be derived from astrocytes, Müller cells, undifferentiated neuroepithelial cells, or endothelial cells. We used antibodies to vimentin, GFAP, carbonic anhydrase, CRALBP, and type IV collagen to distinguish between these various cell types. The majority of the non-neuronal, flat cells in these cultures are immunoreactive for vimentin, carbonic anhydrase, and CRALBP at either 3 or $6 \mathrm{~d}$ in vitro. Since these three antigens are typically localized to Müller cells in the retina (Linser and Moscona, 1981; Shaw and Weber, 1983, 1984; De Leeuw et al., 1990), the cells in culture that are immunoreactive for these molecules are likely to be Müller cells as well. It is also possible that the non-neuronal cells in these cultures are undifferentiated germinal neuroepithelial cells since this cell type also contains vimentin and carbonic anhydrase; however, we consider this unlikely for two reasons. (1) Cultures prepared from animals as late as $10 \mathrm{~d}$ postnatal contain the same cell types, yet these retinas would no longer be expected to contain any undifferentiated neuroepithelial cells, and (2) CRALBP is not found in neuroepithelial cells, only in Müller glia (De Leeuw et al., 1990). Although Müller cells can express GFAP in some species following retinal damage (Eisenfeld et al., 1984), they normally do not express this antigen (Bignami and Dahl, 1979; Bartlettl et al., 1981). Only very few of the non-neuronal cells from neonatal retinas (approximately 2\%) are immunoreactive for GFAP, even after $6 \mathrm{~d}$ in culture (Fig. $1 B$ ). We believe that these are retinal astrocytes that are normally found associated with the vascular membrane in the neonatal rat retina (Watanabe and Raff, 1988). When this layer is dissected and removed from the retina prior to dissociation, the number of GFAP-immunoreactive cells in the culture is significantly reduced compared to cultures where the vascular membrane is left intact. The third type of non-neuronal cell present in the cultures is the capillary endothelial cell. These cells, immunoreactive for type IV collagen both in vivo and in vitro (I. J. Kljavin and T. A. Reh, unpublished observations) also make up approximately $2 \%$ of the non-neuronal cells. Figure $1, B$ and $C$, shows the immunofluorescence of GFAP- and collagen IV-positive cells in the culture.

Rod processes preferentially grow on retinal glial cell surfaces but grow poorly when in contact exclusively with purified ECM as culture substrates

Previous studies of high-density rat retinal cultures have shown that rods grow long processes on "sheets" of flat cells (Akagama and Barnstable, 1986; Araki et al., 1987). In our experiments,

Figure 1. Rods extend neurites preferentially on retinal glia, compared to retinal astrocytes or endothelial cells. Fluorescent micrographs of postnatal day 3 rat retinal cells after $6 \mathrm{~d}$ in culture on laminin $(50 \mu \mathrm{g} /$ $\mathrm{ml})$. $A$, Indirect immunofluorescent labeling of rod cell bodies and processes with the Rho-4D2 antibody (yellow), and the underlying retinal glial cells with a monoclonal antibody to vimentin (red). Rod photoreceptor cells (large arrowhead) grow processes (smaller arrowheads) exclusively on surfaces of non-neuronal cells regardless of substrate. $B$, Astrocytes in whole retinal cultures make up about $2 \%$ of the nonneuronal cell population and are identified with anti-GFAP (large arrow). Rod processes avoid contact with GFAP-positive cells (small arrowheads). Large arrowheads indicate rod on the surface of the astrocyte, with processes growing off and away from this flat cell type. $C$, Endothelial cells in whole retinal cultures also make up about $2 \%$ of the nonneuronal cells and are identified with anti-collagen type IV (broken line
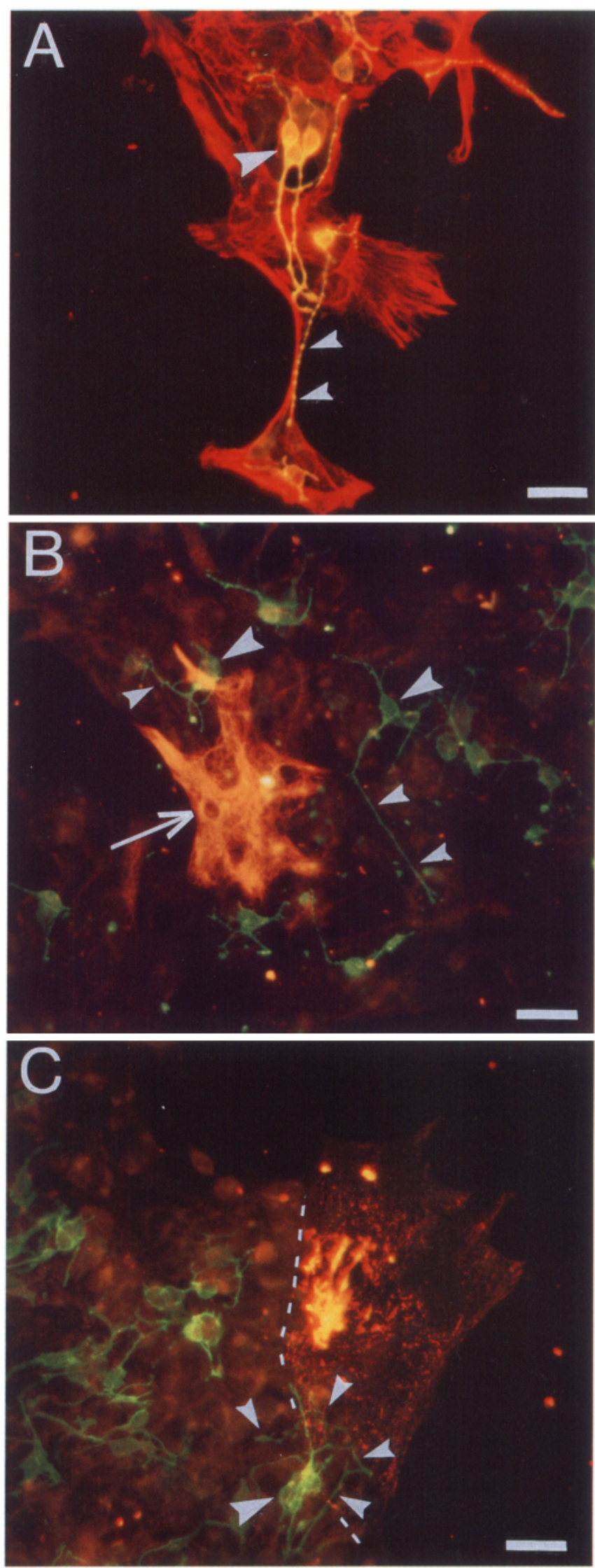

delimits the cell on the right). Rod processes (small arrowheads) may make contact with the collagen IV-positive cells but do not grow over their surfaces. Large arrowhead indicates rod cell bodies. Scale bar, 20 $\mu \mathrm{m}$ in all micrographs. 

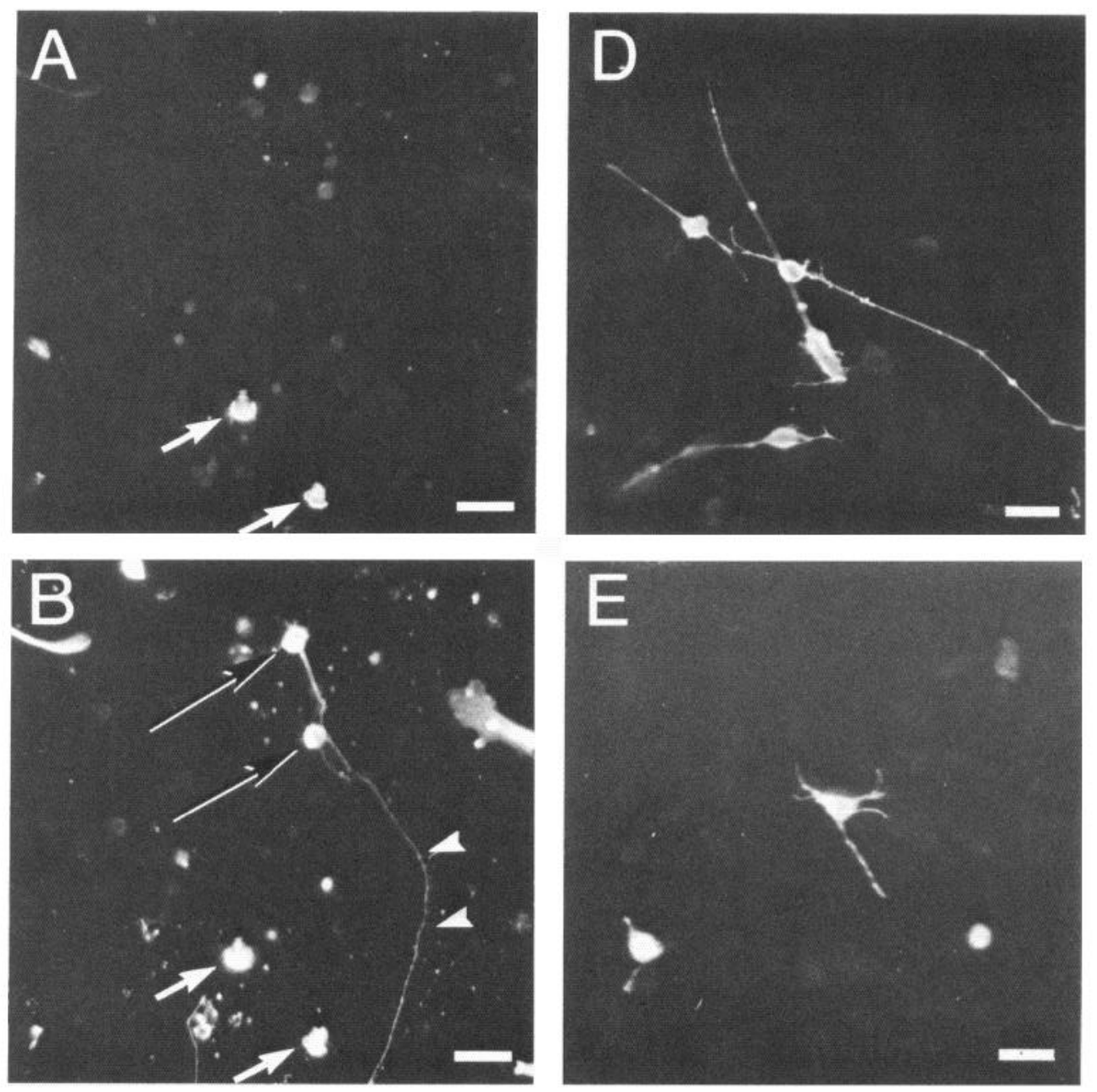

Figure 2. Müller glia are a preferred substrate for process extension of rods. Fluorescent and corresponding phase contrast micrographs of rod photoreceptor cells on Matrigel $(A-C)$ and on cellular substrates consisting of Müller cells $(D)$, astrocytes $(E)$, and 3T3 cells $(F)$. Isolated rods shown labeled with Rho-4D2 ( $A$, small white arrows) fail to grow processes on the Matrigel substrate, whereas other retinal neurons labeled with A2B5 (B, long black/white arrows) grow extensive neurites after 24 $\mathrm{hr}$ in culture (small white arrowheads). Small white arrows in $B$ indicate the same rods shown in $A$, and $C$ is the corresponding phase contrast image. $D$ $F$ show representative fluorescent images of rods growing neurites on Müller cells, astrocytes, and 3T3 cells after 24 $\mathrm{hr}$ in culture. See quantification of these data in Figures $3 B$ and 4 . Scale bar, 20 $\mu \mathrm{m}$ in all micrographs.
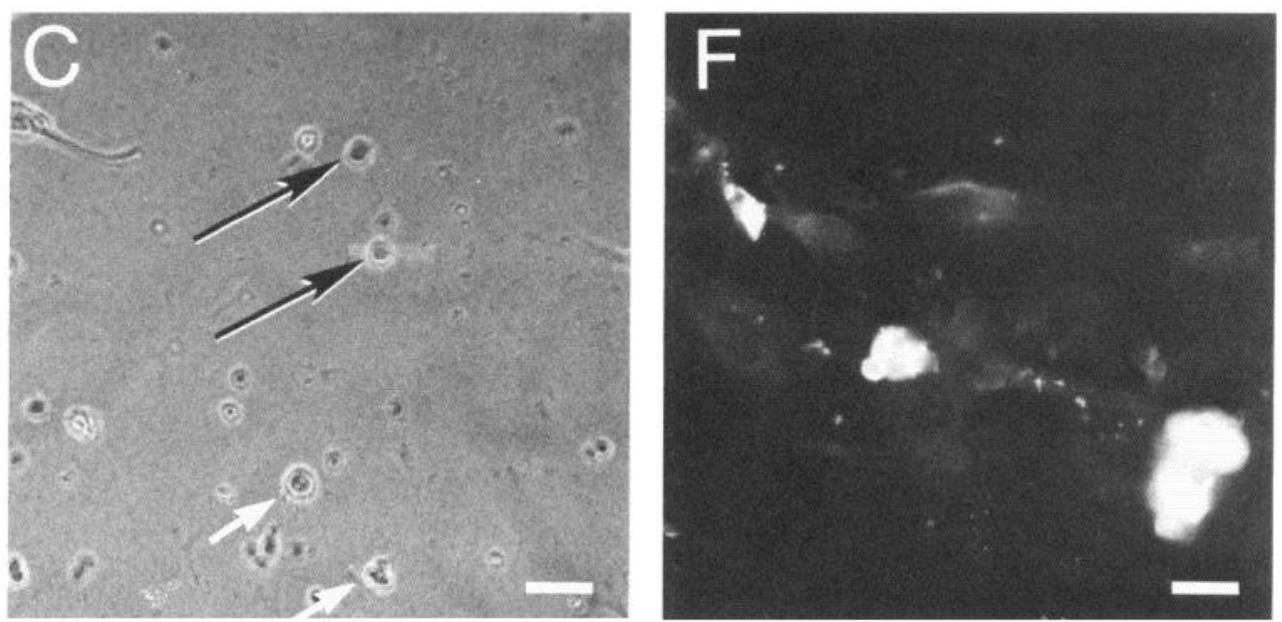

we plated retinal cells at low density onto glass coverslips that were coated with either laminin, Matrigel, fibronectin, or type I collagen to begin to identify adhesive molecules that might mediate rod process outgrowth. In these cultures, some of the cells form aggregates, with both neurons and non-neuronal cells, while other cells remain isolated and are only in contact with their substrate. After culture periods of from 1 to $6 \mathrm{~d}$, the cultures were fixed and labeled with an antibody against vimentin to label all non-neuronal cells in the cultures, as well as with the Rho-4D2 antibody against rhodopsin to label the rods and their processes. As has been described by others previously, the rods grew extensive neurites onto the surfaces of the retinal glia. Approximately $80 \%$ of the rods with processes displayed a bipolar morphology with one long neurite and the other typically shorter as shown in Figure $1 A$. Other rods in the cultures had multiple shorter processes. However, rod processes were always 
A
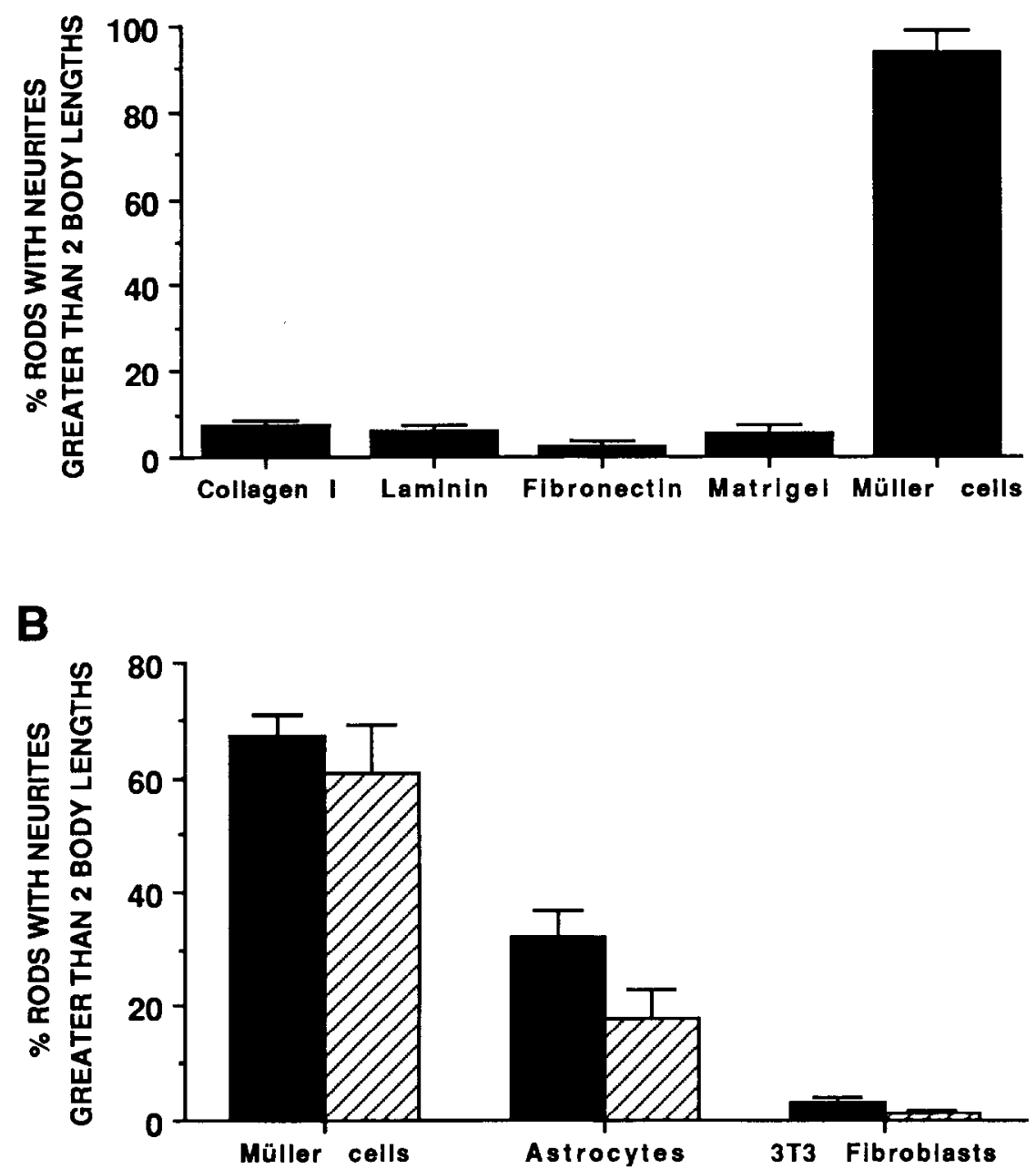

Figure 3. Graph of the ability of various substrates to promote growth of rod processes. $A$, The percentages of rods with processes greater than two cell diameters after $6 \mathrm{~d}$ in culture were calculated and plotted for the different substrates used in this study. Rho-4D2-positive rods were examined in five different fields of view selected at random on each coverslip. Ten coverslips each from different experiments were examined for each of the indicated percentages. The number of rods with processes greater than two cell body diameters in length was determined and was expressed as a percentage of the total number of rods examined. These values are as follows: type I collagen, $7.1 \%(n=433)$; laminin, $5.9 \%(n=$ $505)$; fibronectin, $2.5 \%(n=555)$; and Matrigel, $5.6 \%(n=731)$ of the rods grew processes. Rods adhere to collagen, laminin $(50 \mu \mathrm{g} / \mathrm{ml})$, fibronectin $(50 \mu \mathrm{g} / \mathrm{ml})$, and Matrigel, but most fail to extend processes. By contrast, retinal glial cells are a very effective substrate for rod process extension; $94.1 \%(n=449)$ of the rods in the primary cultures have processes greater than two cell body lengths when growing on the surfaces of Müller glia. $B$. The percentages of rods with processes greater than two cell diameters were also calculated for rods plated on monolayers of Müller cells astrocytes, and 3T3 cells after $24 \mathrm{hr}$ (solid bar) and after $6 \mathrm{~d}$ (hatched bar). Three to eight fields of view were selected at random and examined on each coverslip. A minimum of five coverslips each from different experiments were examined for each of the indicated percentages. The intrinsic retinal glial cell of the retina, the Müller cell, supports a greater percentage of rods with processes greater than two cell body lengths compared to astrocytes or 3T3 cells at either $24 \mathrm{hr}$ or $6 \mathrm{~d}$ in culture. Cell numbers counted for each substrate and time in culture (24 hr, $6 \mathrm{~d}$ ): Müller cells, 138,181 ; astrocytes, 137,$351 ; 3 \mathrm{~T} 3$ fibroblasts, 300,628. A between-group ANOVA showed a reliable effect of group $[F(5,27)=158.566 ; p<0.0001]$. Post hoc pairwise comparisons showed that rod process outgrowth on Müller cells, astrocytes, and 3T3 cells was significantly different (Fisher PLSD, $p<0.05)$. Error bars, \pm SD.

confined to the non-neuronal cell surfaces regardless of the substrate onto which the cells were plated, the time in culture, or serum concentration in the media (Fig. $1 A$ ); when they reached the edge of a glial cell, they did not extend onto the substrate.

By examining isolated cells, we were better able to characterize this observation. While other types of retinal neurons extended long neurites onto various ECM substrates, rods free from contact with retinal glia failed to extend processes greater than two cell diameters in length. The morphological appearance of isolated rods and other retinal neurons labeled with A2B5 and cultured on the Matrigel substrate is shown in Figure $2 A-C$. Note that in Figure $2 A$, rods typically remain as round cells, while other neighboring neurons (Fig. $2 B$ ) extend long neuritic processes. When the number of rods with processes greater than two cell body lengths was quantified for cultures plated onto collagen, laminin, fibronectin, and Matrigel, we found that less than $10 \%$ of isolated rods displayed a process greater than two body lengths on any of the substrates tested after $6 \mathrm{~d}$ in culture (Fig. 3A). By contrast, over $90 \%$ of the rods in contact with a glial cell surface had extended a process. 
Figure 4. Rods cultured on Müller cells have longer neurites compared to those on astrocytes or $3 \mathrm{~T} 3$ cells. The data are represented as the distribution of the percentage of rods with varying process lengths on monolayers of Müller cells $(\square)$, astrocytes $(\times)$, and 3T3 cells $(\triangle)$ after $24 \mathrm{hr}$ in culture. Neurite measurements of Rho-4D2-positive rods with neurites were made as described in Materials and Methods $(N=50$ cells for the Müller cell and astrocyte monolayers, $N=17$ cells for the $3 \mathrm{~T} 3$ cell monolayers).

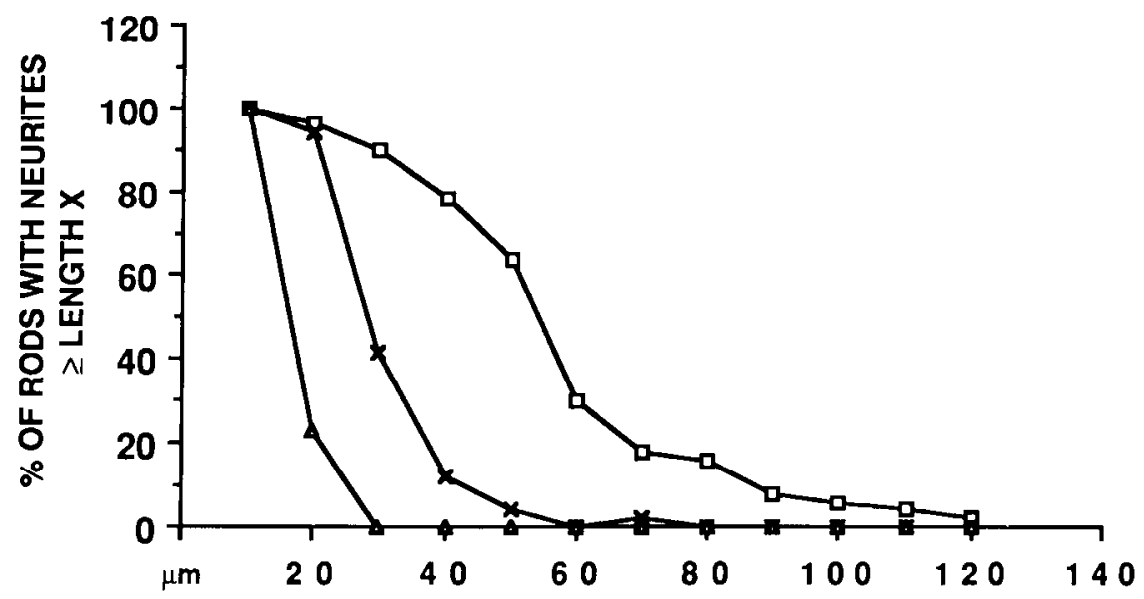

cells, astrocytes, and 3T3 cells, respectively. When plated on the Müller cells (Fig. 2D), rod processes were noticeably longer than when plated on the astrocytes (Fig. $2 E$ ). Most of the rods on the $3 \mathrm{~T} 3$ cells remained round and tended to form clusters (Fig. $2 F$ ). We quantified these observations by calculating the percentage of isolated rods with processes greater than two cell body lengths. After $24 \mathrm{hr}$ in culture, $66.9 \%$ of the rods on the Müller cell monolayers had a process greater than two cell body lengths, while only $32.0 \%$ and $3.0 \%$ of the rods had processes when plated on astrocytes and $3 \mathrm{~T} 3$ cells, respectively (Fig. $3 B$ ). These differences were also noted in experiments where rods were cultured for up to $6 \mathrm{~d}$ on the cellular monolayers; $60.6 \%$ of the rods had processes greater than two cell body lengths when cultured on the Müller cells, while only $17.8 \%$ and $1.3 \%$ of the rods had processes on the astrocytes and 3T3 cells, respectively (Fig. $3 B$ ). We also found that rods had longer neurites when cultured on Müller cell monolayers than when cultured on astrocytes or 3T 3 cells. These data were quantified by measuring the neurite length of rods in these cultures. The lengths of rod neurites are plotted in Fig. 4; both the maximum length of rod processes and the average length are much greater when rods are plated on Müller glia than when they are plated on astrocytes or $3 \mathrm{~T} 3$ cells.

\section{Rods do not extend neurites on the surfaces of other retinal neurons}

To characterize further the apparently selective growth of rods on Müller glia, we carried out an additional experiment to determine whether rods grow processes along the neurites of other cultured neurons. To suppress Müller glia proliferation and spreading, we plated the dissociated retinal cells onto poly-Dlysine- or laminin-coated coverslips in low-serum conditions or with AraC added to the cultures (see Materials and Methods). Under these conditions, approximately $20-40 \%$ of the retinal neurons extended neurites within $24 \mathrm{hr}$ of plating, while the spreading of non-neuronal cells was limited. The cultures were fixed after 24-30 hr and labeled with the monoclonal antibodies A2B5 (neuron-specific antibody) and Rho-4D2. Figure 5 shows the typical appearance of these cultures. As noted above (Fig. $3 A$ ), rods extended processes only when in contact with a glial cell (Fig. $5 A, D$ ). Other retinal neurons, however, did grow extensive processes with varying morphologies; some neurons displayed several short neurites and other neurons had single long processes (Fig. $5 C, F$ ). When we confined our analysis to those on the astrocyte or 3 T 3 cell monolayers. Figure $2, D-F$, shows the typical appearance of rods after $24 \mathrm{hr}$ in culture on Müller 

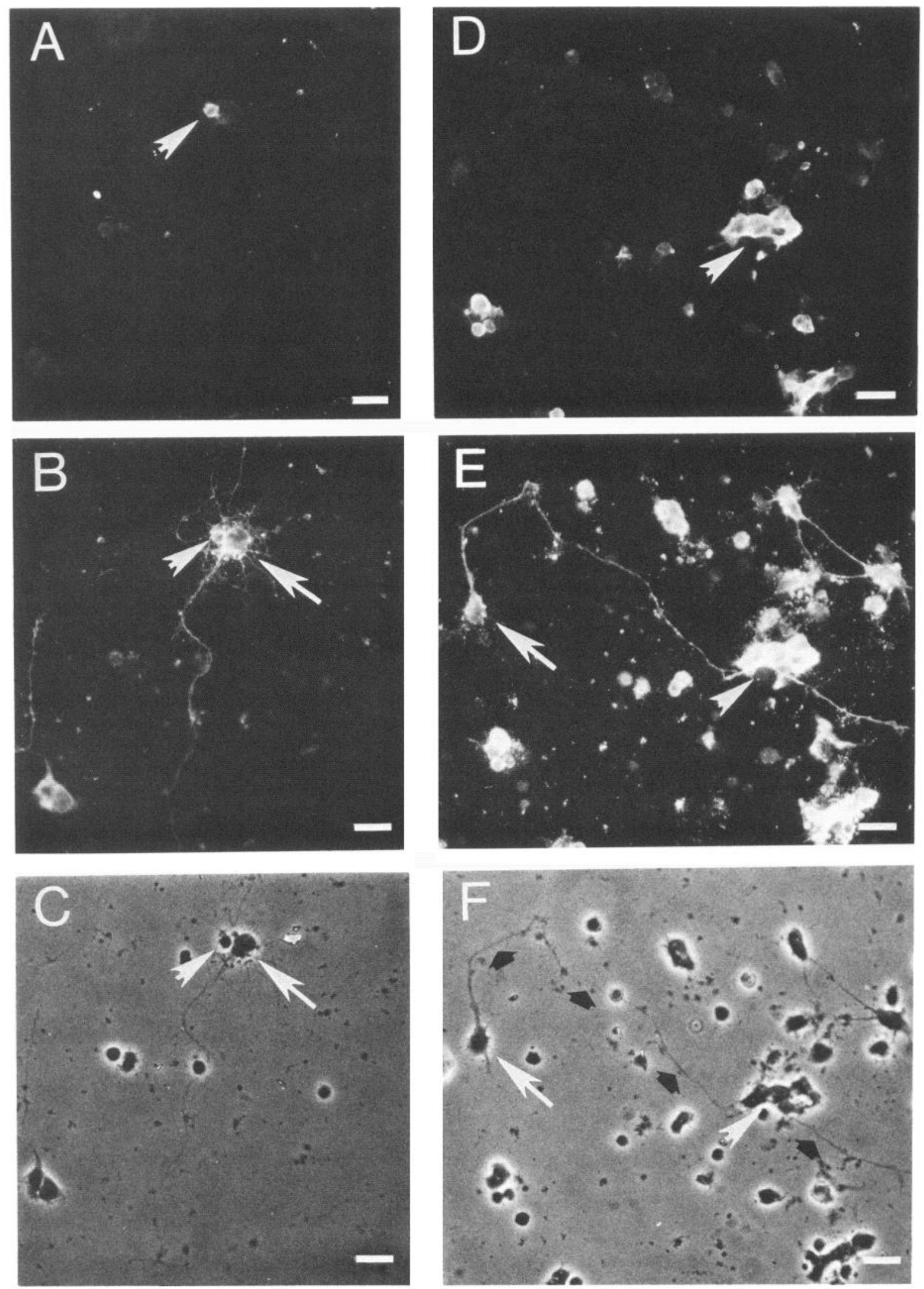

Figure 5. Rods do not extend processes onto the surfaces of other retinal neurons in culture. Fluorescent and corresponding phase contrast micrographs of opsin-immunoreactive rod photoreceptor cells $(A$ and $D)$ and A2B5-immunoreactive neurons $(B$ and $E)$ from postnatal day 3 rats. The cultures were prepared under conditions for minimal glial cell spreading while allowing for substantial neurite outgrowth from other retinal neurons. Under these culture conditions, free from glial cell spreading, we could determine if rods were able to extend processes out onto neuronal cell surfaces alone. Rods (arrowheads) in contact with other retinal neurons (large white arrows) fail to extend processes on the neurites of other cells in the culture. $A-C$ are of corresponding fields, as are D-F. Small black arrows in $F$ indicate the neurite from the A2B5-positive neuron shown in the corresponding fluorescent image in $E$. Scale bar, $20 \mu \mathrm{m}$ in all micrographs. 
rods in contact with other retinal neurons, we found that rods did not extend processes greater than two cell body lengths growing on any part of another neuron. Figure $5(A, B$ and $D, E)$ shows two examples of this typical observation. In eight experiments, with a total of 32 rod-neuron interactions, only two rods had a process greater than two cell body lengths when in contact exclusively with another retinal neuron.

\section{Discussion}

Müller cells provide a better substrate than ECM molecules for the growth of rod neurites

The first finding of this study is that rods extend neurites preferentially on glial cell surfaces. The various ECM components that we tested, while promoting neurite extension from other types of retinal neurons, were much less effective as growth substrates for rod processes. This result stands somewhat in contrast to previous studies of retinal neurons in culture, in which ECM components were found to be effective substrates for neurite outgrowth (Rogers et al., 1983; Adler et al., 1985). For example, laminin substrates can promote neurite outgrowth from chick retinal neurons (Cohen et al., 1987; Hall et al., 1987; Neugebauer et al., 1988); moreover, neurite extension of both embryonic day 7 (E7) and E1 1 chick retinal neurons on astrocyte monolaycrs can bc reduced by antibodies to ECM receptors (Neugebauer et al., 1988). Nevertheless, it is apparent that not all neuronal classes of the retina respond to the same microenvironmental conditions. For example, while many of the neurons cultured from embryonic chick or rat retinas can extend processes on ECM components, such as laminin or collagen, a certain proportion of retinal neurons do not (Adler et al., 1985; Hall et al., 1987; Neugebauer et al., 1988). Our data would indicate that rod photoreceptor cells would be among those neurons that generally may not respond to laminin, fibronectin, type I collagen, or an ECM-rich basement membrane.

Could the lack of a soluble trophic factor from Müller cells explain the inability of rods to extend processes on purified ECM components? Several recent studies have shown that glial cells secrete neurite-promoting factors. For example, Hatten et al. (1988) have shown that bFGF secreted by astrocytes will promote neuritc outgrowth from ccrebcllar cells in culture. However, we do not think that this is a likely explanation for the inability of rods to extend neurites onto the substrates, since even those rods growing on top of glia did not extend processes onto the various ECM molecules. In addition, even in highdensity cultures, where the presence of glial secreted molecules should be concentrated, isolated rods did not grow neurites onto the substrate. Although some specific growth factors like FGF can stimulate extensive process outgrowth from retinal ganglion cells in vitro (Lipton et al., 1988), studies of other classes of retinal neurons have failed to demonstrate a role for FGF in the promotion of neurite outgrowth (Schubert et al., 1987). In particular, Hicks and Courtois (1988) specifically examined the effects of FGF on rat rod photoreceptor cells in culture and concluded that while this molecule can enhance survival of rods there is no effect on "fibre outgrowth."

It is pcrhaps not so surprising that the factors regulating the growth of projection neurons and intrinsic neurons differ. As noted in the introductory remarks, the growth cones of the retinal ganglion cells, like those of other projection neurons, come in contact with the end feet of the neuroepithelial cells, as well as astroglia in the developing white matter pathways. Many of the molecules that are responsible for regulating the growth of ganglion cell axons during development are concentrated on the neuroepithelial cell end feet along these long tracts (Halfter et al., 1988). By contrast, rods do not extend axons into long pathways, but rather, their axons terminate on neighboring cells, the bipolar and horizontal cells. They will, therefore, never come into contact with the end feet of the neuroepithelial cells or the astrocytes of the ganglion cell fiber layer and optic nerve. If this result can be generalized to other types of local circuit neurons, we speculate that ECM components that promote neurite outgrowth may only do so for projection neurons.

\section{Müller cells provide a better substrate than neurons or other non-neuronal cells for the growth of rod neurites}

Previous studies of retinal cells in culture have noted that most neurons, including rods, can elaborate processes onto retinal glial cells (McCaffery et al., 1984; Akagama and Barnstable, 1986; Araki et al., 1987; Drazba and Lemmon, 1990), and astrocytes have been shown to support neurite outgrowth from retinal explants and up to $60 \%$ of the neurons from dissociated chick retina (Fallon, 1985). In the present study, we found that Müller cells were the best cellular substrate at promoting the growth of processes from rods, when compared to neuronal cell surfaces alone or other non-neuronal cells. Specifically, rod processes appear to grow poorly on endothelial cell or 3T3 ccll surfaces compared to Müller cells or astrocytes. These findings suggest that rods have a preference for extending neurites onto glial cells as compared with nonglial cell surfaces, a characteristic shared by other CNS neurons. For example, when cerebellar or spinal cord neurons are plated on glial cells, they show significantly more neurite outgrowth than when plated on nonglial cells (Noble et al., 1984; see also Fallon, 1985).

However, we have found that Müller cells and astrocytes differ in their ability to promote process extension from rods. When rods were cultured on Müller cells, a higher percentage had neurites, and in addition, the average length of the neurites was considerably greater. This apparent preference of rods for Müller glial surfaces may be relevant to the normal sequence of retinal histogenesis. As noted in the introductory remarks, Hinds and Hinds (1979) have shown that after rounding up at their terminal mitosis, photoreceptor cells reextend their vitreal/presynaptic terminal process. This process is in some ways analogous to the growth of the leading process of migrating neuroblasts along radial glia in other areas of the CNS. Since rods and Müller cells arise at approximately the same time during retinal development (Sidman, 1961; Carter-Dawson and LaVail, 1979; Turner and Cepko, 1988; Zimmerman et al., 1988) and likely are in contact with one another, our finding that Müller cells are better than astrocytes in promoting rod process outgrowth may represent an example of regional specificity for the glial-mediated promotion of neurite outgrowth. Such a preference of neurons within a particular region of the CNS for glial cells within that same region has been noted previously; mesencephalic and striatal neurons will mature faster and develop a more profuse and highly branched dendritic-like arborization when these neurons are cocultured with astrocytes derived from the same brain region (Denis-Donini et al., 1984; Chamak et al., 1987). Additional evidence for heterogeneity in the growth-promoting abilities of CNS glia comes from the study of Denis-Donini and Estenoz (1988), in which neurons from the substantia nigra were found to extend longer neurites when plated on olfactory bulb glia than when plated on glia derived from other brain regions. Regional differences in astrocytic surface glycoproteins offer a potential 
molecular basis for these tissue culture observations (Barbin et al., 1988).

The fact that Müller cells are preferred as a substrate for rod process extension can be explained if Müller cells were found to have on their surfaces novel cell adhesion molecules not found on, for example, astrocytes. Alternatively, Müller cells may contain cell adhesion molecules similar to astrocytes, such as NCAM or $\mathrm{N}$-cadherin, but instead contain greater amounts or more adhesive molecular forms of these molecules (see, e.g., Chuong and Edelman, 1984). Further experiments will be necessary to distinguish between these alternatives. At the present time, we can only say that compared with astrocytes, non-glia, retinal neurons, or pure ECM molecules alone, the intrinsic retinal glia are superior at promoting the process extension and formation of neurites in vitro for at least one class of intrinsic retinal ncuron, the rod photoreceptor cell.

\section{References}

Adler R, Jerdan J, Hcwitt AT (1985) Responses of cultured neural retinal cells to substrata-bound laminin and other extracellular matrix molecules. Dev Biol 112:100-114.

Akagama K, Barnstable CJ (1986) Identification and characterization of cell types in monolayer cultures of rat retina using monoclonal antibodies. Brain Res 383:110-120.

Araki M, Iida Y, Taketami S, Watanabe M, Ohta K, Saito J (1987) Characterization of photoreceptor cell differentiation in the rat retinal cell culture. Dev Biol 124:239-247.

Barbin G, Katz DM, Chamak B, Glowinski J, Prochiantz A (1988) Brain astrocytes express region-specific surface glycoproteins in culture. Glia 1:96-103.

Bartlett PF, Noble MD, Pruss RM, Raff MC, Rattray S, Williams CA (1981) Rat neural antigen-2 (RAN-2): a cell surface antigen on astrocytes, ependymal cells, Müllcr cclls and leptomeninges defined by monclonal antibody. Brain Res 204:339-351.

Bignami A, Dahl D (1979) The radial glia of Müller in the rat retina and their response to injury: an immunofluorescence study with antibodies to glial fibrillary acidic (GFA) protein. Exp Eye Res 28:6369.

Bunt-Milam AH, Sarri JC (1983) Immunocytochemical localization of two retinoid-binding proteins in vertebrate retina. J Cell Biol 97: 703-712.

Carter-Dawson LD, LaVail MM (1979) Rods and cones in the mouse retina. II. Autoradiographic analysis of cell generation using tritiated thymidine. J Comp Neurol 188:263-272.

Chamak B, Fellows A, Glowinski J, Prochiantz A (1987) MAP2 expression and neuritic outgrowth and branching are co-regulated through region specific neuro-astroglial interactions. J Neurosci 7:3163-3170.

Chuong C, Edelman G (1984) Alterations in neural cell adhesion molecules during development of different regions of the nervous system. J Neurosci 4:2354-2368.

Cohen J, Burne JF, McKinlay C, Winter J (1987) The role of laminin and the laminin/fibronectin receptor complex in the outgrowth of retinal ganglion cell axons. Dev Biol 122:407-418.

De Leeuw AM, Gaur VP, Saari JC, Milam AH (1990) Immunolocalization of cellular retinol-, retinaldehyde- and retinoic acid-binding proteins in the retina during pre- and postnatal development. J Neurocytol 19:253-264.

Denis-Donini S, Estenoz M (1988) Interneurons versus efferent neurons: heterogeneity in their neurite outgrowth response to glia from several brain regions. Dev Biol 130:237-249.

Denis-Donini S, Glowinski J, Prochiantz A (1984) Glial heterogencity may define the three dimensional shape of mouse mesencephalic dopaminergic neurons. Nature 307:641-643.

Drazba J, Lemmon V (1990) The role of cell adhesion molecules in neurite outgrowth on Müller cells. Dev Biol 138:82-93.

Easter SS, Bratton B, Scherer SS (1984) Growth-related order of the retinal fiber layer in goldfish. J Neurosci 4:2173-2190.

Eisenfeld AJ, Bunt-Milam AH, Sarthy PV (1984) Müller cell expression of glial fibrillary acidic protein after genetic and experimental photoreceptor degeneration in the rat retina. Invest Ophthalmol Vis Sci 25:1321-1328.
Fallon JR (1985) Preferential outgrowth of central nervous system neurites on astrocytes and Schwann cells as compared with nonglial cells in vitro. J Cell Biol 100:198-207.

Foellmer HG, Maadri JA, Furthmayr H (1983) Monoclonal antibodies to type IV collagen: probes for the study of structure and function of basement membranes. Lab Invest 48:639-649.

Halfter W, Diamantis I, Monard D (1988) Migratory behavior of cells on embryonic retina basal lamina. Dev Biol 130:259-275.

Hall DE, Neugebauer KM, Reichardt LF (1987) Embryonic neural retinal cell response to extracellular matrix proteins: developmental changes and effects of the cell substratum attachment antibody (CSAT). Cell Biol 104:623-634.

Hatten ME, Lynch M, Rydel RE, Sanchez J, Joseph-Silverstein J, Moscatelli D, Rifkin DB (1988) In vitro neurite extension by granule neurons is dependent upon astroglial-derived fibroblast growth factor. Dev Biol 125:280-289.

Hicks D, Barnstable C (1987) Different rhodopsin monoclonal antibodies reveal different binding patterns on developing and adult rat retina. J Histochem Cytochem 35:1317-1328.

Hicks D, Courtois Y (1988) Acidic fibroblast growth factor stimulates opsin levels in retinal photoreceptor cells in vitro. FEBS Lett 234: $475-479$.

Hinds JW, Hinds PL (1979) Differentiation of photoreceptors and horizontal cells in the embryonic mouse retina: an electron microscopic, serial section analysis. J Comp Neurol 187:495-512.

Krayanek S, Goldberg S (1981) Oriented extracellular channels and axonal guidance in the embryonic chick retina. Dev Biol 84:41-50.

Liesi P (1985) Do neurons in the vertebrate CNS migrate on laminin? EMBO J 4:1163-1170.

Linser P, Moscona AA (1981) Carbonic anhydrase-C in the neural retina: transition from generalized to glia-specific cell localization during embryonic development. Proc Natl Acad Sci USA 78:71907194.

Lipton SA, Wagner JA, Madison RD, D'Amore PA (1988) Acidic fibroblast growth factor enhances regeneration of processes by postnatal mammalian retinal ganglion cells in culture. Proc Natl Acad Sci USA 85:2388-2392.

McCaffery CA, Raju TR, Bennett MR (1984) Effects of cultured astroglia on the survival of neonatal rat retinal ganglion cells in vitro. Dev Biol 104:441-448.

McLoon S, McLoon LK, Palm SL, Furcht LT (1988) Transient expression of laminin in the optic nerve of the developing rat. J Neurosci 8:1981-1990.

Neugebauer KM, Tomaselli KJ, Lilien J, Reichardt LF (1988) $\mathrm{N}$-cadherin, NCAM and integrins promote retinal neurite outgrowth on astrocytcs in vitro. J Cell Biol 107:1177-1187.

Noble M, Fok-Seang J, Cohen J (1984) Glia are a unique substrate for the in vitro growth of central nervous neurons. J Neurosci 4:18921903.

Ragar GH (1980) Development of the retinotectal projection in the chicken. Adv Anat Embryol Cell Biol 63:63.

Raper JA, Kapfhammer JP (1990) The enrichment of a neuronal growth cone collapsing activity from embryonic chick brain. Neuron 2:21-29.

Rogers SL, Letourneau PC, Palm SL, McCarthy J, Furcht LT (1983) Neurite extension by peripheral and central nervous system neurons in response to substratum-bound fibronectin and laminin. Dev Biol 98:212-220.

Sarthy PV (1985) Establishment of Müller cell cultures from adult rat retina. Brain Res 337:138-141.

Schubert D, Ling N, Baird A (1987) Multiple influences of a heparinbinding growth factor on neuronal development. J Cell Biol 104:635643.

Shaw W, Weber K (1983) The structure and development of the rat retina: an immunofluorescence microscopical study using antibodies specific for intermediate filament proteins. Eur J Cell Biol 30:219232.

Shaw W, Weber K (1984) The intermediate filament complement of the retina: a comparison between different mammalian species. Eur J Cell Biol 33:95-104.

Sidman R, Wessels N (1975) Control of direction of growth during elongation of neurites. Exp Neurol 48:237-251.

Sidman RL (1961) Histogenesis of mouse retina studied with thymidine-H3. In: The structure of the eye (Smelser G, ed), pp 487-506. New York: Academic. 
Silver J, Rutishauser U (1984) Guidance of optic axons in vivo by a preformed adhesive pathway on neuroepithelial endfeet. Dev Biol 106:485-499.

Silver J, Sapiro J (1981) Axonal guidance during development of the optic nerve: the role of pigmented epithelia and other extrinsic factors. J Comp Neurol 202:521-538.

Silver J, Sidman RL (1980) A mechanism for the guidance and topographic patterning of retinal ganglion cell axons. J Comp Neurol 189:101-111.

Silver J, Lorenz SE, Wahlsten D, Coughlin J (1982) Axonal guidance during development of the great cerebral commissures: descriptive and experimental studies, in vivo, on the role of preformed glial pathways. J Comp Neurol 210:10-29.

Turner DL, Cepko CL (1988) A common progenitor for neurons and glia persists in rat retina late in development. Nature 328:131-136.

Watanabe T, Raff MC (1988) Retinal astrocytes are immigrants from the optic nerve. Nature 332:834-837.

Zimmerman RP, Polley EH, Fortney RL (1988) Cell birthdays and rate of differentiation of ganglion and horizontal cells of the developing cat's retina. J Comp Neurol 274:77-90. 